OPEN ACCESS

Edited by:

Mary Helen Barcellos-Hoff, University of California, San Francisco,

United States

Reviewed by:

Hyuk-Jin Cha,

Seoul National University, South Korea

Gianluca Baldanzi,

Università Piemonte Orientale, Italy

Elena Rainero,

University of Sheffield,

United Kingdom

*Correspondence:

Odilia Popanda

o.popanda@dkfz-heidelberg.de

Specialty section:

This article was submitted to

Radiation Oncology

a section of the journal

Frontiers in Oncology

Received: 07 February 2020

Accepted: 17 April 2020

Published: 12 May 2020

Citation:

Liu C-S, Schmezer $P$ and Popanda $O$ (2020) Diacylglycerol Kinase Alpha in Radiation-Induced Fibrosis: Potential as a Predictive Marker or Therapeutic

Target. Front. Oncol. 10:737.

doi: 10.3389/fonc.2020.00737

\section{Diacylglycerol Kinase Alpha in Radiation-Induced Fibrosis: Potential as a Predictive Marker or Therapeutic Target}

\author{
Chun-Shan Liu, Peter Schmezer and Odilia Popanda* \\ Division of Cancer Epigenomics, German Cancer Research Center (DKFZ), Heidelberg, Germany
}

Radiotherapy is an efficient tool in cancer treatment, but it brings along the risk of side effects such as fibrosis in the irradiated healthy tissue thus limiting tumor control and impairing quality of life of cancer survivors. Knowledge on radiation-related fibrosis risk and therapeutic options is still limited and requires further research. Recent studies demonstrated that epigenetic regulation of diacylglycerol kinase alpha (DGKA) is associated with radiation-induced fibrosis. However, the specific mechanisms are still unknown. In this review, we scrutinized the role of DGKA in the radiation response and in further cellular functions to show the potential of DGKA as a predictive marker or a novel target in fibrosis treatment. DGKA was reported to participate in immune response, lipid signaling, exosome production, and migration as well as cell proliferation, all processes which are suggested to be critical steps in fibrogenesis. Most of these functions are based on the conversion of diacylglycerol (DAG) to phosphatidic acid (PA) at plasma membranes, but DGKA might have also other, yet not well-known functions in the nucleus. Current evidence summarized here underlines that DGKA activation may play a central role in fibrosis formation post-irradiation and shows a potential of direct DGKA inhibitors or epigenetic modulators to attenuate pro-fibrotic reactions, thus providing novel therapeutic choices.

Keywords: radiotherapy, late adverse effects, fibrosis, lipid signaling, diacylglycerol, phosphatidic acid

\section{INTRODUCTION}

Radiotherapy is a valuable part of cancer treatment; more than $50 \%$ of all cancer patients receive radiation therapy at some point during their treatment for curative or palliative purposes $(1,2)$. Ionizing radiation (IR) is given to kill tumor cells but radiation also targets the surrounding normal tissue resulting in tissue damage (radiation injury) and development of adverse side effects (3). Within hours to weeks after radiation, an acute tissue response occurs but late adverse effects may appear even after months or years post-therapy. Early radiation effects include DNA damage, cell cycle arrest and cell death which will lead to cell loss, endothelial and tissue damage and inflammation. During this stage of tissue destruction, chemokines, and cytokines are emitted to activate a wound healing response. Fibroblast to myofibroblast trans-differentiation, extracellular matrix (ECM) production and angiogenesis occur, resulting in cell proliferation and tissue regeneration. Once tissue repair is completed, the inflammatory response is resolved, activated myofibroblasts are deactivated by cellular senescence or cell death and the damaged area should 
turn back to a normal tissue phenotype (4). However, in a considerable number of irradiated patients, the wound healing response after radiation is maintained for longer leading to scars, tissue indurations and contractions, fibrosis, and in some cases, organ failure. Thus, side effects might strongly affect quality of life of cancer survivors and can even be a deadly threat. Some examples revealing the clinical relevance of radiation-induced fibrosis should shortly be mentioned here.

Regarding the lung, radiotherapy of the thorax is strongly limited by radiation-induced early side effects in the organ like acute radiation pneumonitis which even may cause interruption or premature termination of therapy (5-8). Over a period of 1-2 years post-treatment, radiation-induced alterations in the lung may lead to destruction of lung architecture or deletion of specific lung cells like alveolar cells involved in oxygen exchange. Together with the accumulation of fibrotic tissue forming a "scar," these alterations may cause dyspnea, oxygen starvation, and even organ failure and dead (9). Such severe late side effects occur in about $5-20 \%$ of patients, and despite considerable technical efforts in targeting specifically the tumor, they are limiting the applicable dose in lung or esophageal cancer even at the cost of tumor control.

Also in head and neck cancer patients, radiation-induced fibrosis can occur. In a Belgian study, $68 \%$ of cancer patients treated with radiotherapy showed mild-to-severe neck fibrosis with an increasing risk for this side effect with every year after therapy (10). In these patients, again, fibrotic side effects can be rather harmful according to the affected site, for example they strongly affect oral mucosae and swallowing and thus adequate food intake.

Chronic fibrosis is also frequently identified in breast cancer patients. About $21 \%$ of breast cancer patients developed fibrosis 8 years after they obtained an intra-operative boost radiotherapy (11). In these patients, fibrosis can result in cosmetic changes of the breast but also severe and harmful endurations and limited mobility. Overall, these examples show that tissue fibrosis is a severe side effect of radiotherapy strongly affecting therapy success but also quality of life in cancer survivors.

In general, the molecular mechanisms leading to radiationinduced fibrosis are expected to be similar to those of other fibrotic diseases in the liver, kidney, lung, or heart. Radiation causes the initial tissue injury by directly damaging DNA and by generating reactive oxygen or nitrogen species (ROS or RNS) which will react with DNA but also with other cellular components like membranes and lipids (12). Besides escaping to senescence, the damaged cells can undergo cell death and represent a severe tissue damage which triggers the wound healing response. They may cause inflammation and release of inflammatory chemokines and cytokines which activate neutrophils, lymphocytes, and monocytes as well as endothelial cells and resident macrophages, stromal fibroblasts, and further mesenchymal cells $(13,14)$. As in other fibrotic processes, the secretion of tumor growth factor beta (TGF$\beta$ ) or platelet-derived growth factor (PDGF) promotes the development of myofibroblasts expressing alpha-smooth muscle actin ( $\alpha$-SMA) and producing excess ECM proteins like collagens with an increased stability of ECM. Enrichment of ECM and myofibroblasts results in manifestation of indurations and limited tissue functions.

Although many of the released cytokines like TGF- $\beta$, IL6 and IL-10 are well-known pro-fibrotic triggers leading to myofibroblast activation (15), the steps resulting in the elongation or even perpetuation of wound healing processes are mostly unknown.

Further cellular components, the phospholipids, are reported to be involved in radiation-induced fibrogenesis. In primary human dermal fibroblasts, phospholipids such as phosphatidylcholine (PC) and phosphatidylethanolamine (PE) are increased after gamma-irradiation (16). A further bioactive phospholipid, lysophosphatidic acid (LPA) is synthesized from PC and is suggested to be a pro-fibrotic factor in radiationinduced fibrosis $(17,18)$. Another LPA precursor is phosphatidic acid (PA) which is converted from diacylglycerol (DAG) by diacylglycerokinases (DGKs). Increased PA levels trigger the generation of LPA which is involved in many chronic inflammatory diseases including idiopathic pulmonary fibrosis and liver fibrosis $(19,20)$. In irradiated mice as well as in cell cultures, supplementation with LPA reduced irradiationinduced apoptosis (21). LPA functions include stimulation of cell proliferation, activation of pro-fibrotic responses and anti-apoptotic mechanisms by LPA receptor-mediated extracellular signal-regulated kinase (ERK) activation (18). Thus, targeting LPA with antibodies or antagonists against its receptor LPAR could make it a valuable target for novel therapeutic anti-fibrotic approaches. Hence, a LPA type 2 receptor antagonist, octadecenyl thiophosphate (OTP), could attenuate irradiation-induced apoptosis and activate antiapoptotic ERK signaling which both are leading to increased cell survival (21).

During fibroblast transactivation, epigenetic mechanisms are involved in activating the appropriate transcriptional reprogramming in the affected cells (22). Epigenetic variation might predispose patients for developing a prolonged tissue response. Changes in post-translational histone marks and miRNAs have been described $(23,24)$. Epigenetic changes during such reprogramming processes can be reverted not only by intrinsic mechanisms but also by epigenetic drugs. Thus, this might offer possibilities to attenuate fibrotic processes and alleviate reconstitution of normal tissue characteristics. Epigenetic therapies might be helpful substitutions to current treatment options for radiation-induced fibrosis. These include small molecules and even stem cells and target the different specific steps of fibrogenesis, however only some of them are in clinical use $(9,25,26)$. Examples are antioxidants and radical scavengers which are applied to protect the irradiated normal tissue from damage through radiolysis of water and other cellular components (25). Especially drugs already approved for clinical application for other purposes like hesperidin, rutin, or melatonin could easily be included in therapeutic schedules [for a recent summary, see (25)]. Currently, amifostine acting as a radical scavenger is the only FDA-approved cytoprotective drug used in head and neck cancer patients. Its use for lung protection shows ambiguous results (5). Further treatments include anti-inflammatory drugs like glucocorticosteroids to 
repress the immune response activated in the damaged tissue (27). Molecular therapies targeting pro-fibrotic players like the fibrosis driver TGF- $\beta$ or the connective tissue growth factor (CTGF) are promising but still in preclinical testing $(26,28,29)$. Further approaches are using mesenchymal stem cells (MSCs) for tissue regeneration (9). In preclinical models, MSCs not only replace damaged lung epithelial cells but also promote tissue repair through the secretion of anti-inflammatory and anti-fibrotic factors. They can even be genetically modified, e.g., by over-expression of the radical scavenging enzyme superoxide dismutase, to improve their radioprotective potential. First clinical trials in patients with idiopathic pulmonary fibrosis are encouraging. There are however strong concerns about the safety of such a therapy. Therefore, further investigations to identify novel molecular targets for radioprotective and antifibrotic treatments are urgently needed to improve personalized radiotherapy.

\section{DIACYLGLYCEROL KINASE ALPHA (DGKA) AS A POTENTIAL CANDIDATE IN RADIATION-INDUCED FIBROSIS}

A cohort of breast cancer patients undergoing intraoperative radiotherapy were observed for occurrence of adverse side effects with a median follow-up time of 4.9 years (range 2.0-5.5) (30). For each patient, skin fibroblasts were cultivated. DNA methylation patterns were determined from patients who did or did not develop radiation-induced fibrosis using Illumina $450 \mathrm{~K}$ arrays (31). A number of differentially methylated sites was identified, among them an intragenic enhancer in the DGKA gene. Low methylation at this site was associated with moderate to severe fibrosis (LENT-SOMA grade 2-3) and high methylation with mild to no reaction $(31,32)$. A more detailed analysis revealed that the radiation-inducible transcription factor EGR1 was able to bind to the differentially methylated region thereby inducing DGKA expression in fibroblasts which then expressed enhanced levels of the pro-fibrotic ECM proteins collagen and fibronectin. DGKA is involved in lipid signaling, cell migration and cell growth (33). It is expressed in normal $\mathrm{T}$ cells, spleen and skin as well as in cancer cells but it was not yet described in the context of fibrosis. Several inhibitors are known for this protein making it an attractive target in the fight against fibrosis. To further boost studies of DGKA and fibrosis development, the known characteristics of DGKA are summarized in the following.

\section{DIACYLGLYCEROL KINASES, FUNCTION, AND STRUCTURE}

DGKA is part of a family of mammalian diacylglycerol kinases (DGKs) which includes 10 isoforms grouped into five subtypes. DGKs convert diacylglycerol (DAG) to phosphatidic acid (PA), which both are lipids with important and far-reaching signaling properties [Figure 1; (33-37)]. Thus, DGKs terminate DAGregulated signals and activate PA-regulated ones. These two lipids are generated at the membrane and act as hot spots to localize and activate numerous signaling cascades $(38,39)$. In mammals, on the one hand, DGKs act as negative modulators of classical protein kinase $\mathrm{C}(\mathrm{cPKC} ; \mathrm{PKC} \alpha, \beta$, and $\gamma$ ) and novel PKC isoforms (nPKC; PKC $\delta, \varepsilon, \eta$, and $\theta$ ), protein kinase $\mathrm{D}(\mathrm{PKD})$, and guanyl nucleotide-releasing protein for Ras (RasGRP) $(40,41)$. On the other hand, DGKs-induced PA promotes the activation of mammalian target of rapamycin (mTOR), atypical PKC (aPKC, $\mathrm{PKC} \zeta$, and $\mathrm{PKC} / \mathrm{\kappa})$, and phosphatidylinositol-4-phosphate 5kinase (PIP5K) (42).

All DGKs contain at least two cysteine-rich $\mathrm{C} 1$ like domains and a highly conserved catalytic domain (43). The C1 domains in DGKs originally contribute to DAG-dependent binding to the membrane. The catalytic domain is a common domain in all DGKs with a highly conserved motif " $\phi \phi \phi G G D G T$ " $(\phi$ indicates any hydrophobic residue) that involves ATP binding (44). Each DGK subtype contains accessory regulatory motifs in its primary sequence that might divert their function, regulation and localization. There are numerous reviews on DGKs (34, 43, 45-48) but here we are focusing on DGKA which belongs to type I DGKs that specifically contain a $\mathrm{Ca}^{2+}$-dependent regulatory domain at its $\mathrm{N}$-terminus including a recoverin-like domain (RVH) and two EF-hand motifs.

\section{CELLULAR MECHANISMS TO MODULATE DGKA RNA EXPRESSION}

DGKA levels differ considerably in various tissues. Transcripts are enriched in lymphoid tissues especially lymph nodes, tonsils and spleen, as well as in skin, esophagus, duodenum and small intestine (Figure 2A). Expression is low in primary melanocytes, hepatocytes, and neurons (49-51) and in the corresponding tissues like liver, brain, kidney, heart and skeletal muscle, suggesting tissue-specific functions of the protein. This is confirmed by the evaluation of immunohistochemistry images of DGKA protein in human tissue sections (Figure 2B). They show heterogeneous amounts of DGKA in the different cell types constituting the various tissues. In contrast, DGKA expression is strongly increased in tumors like melanoma, hepatocarcinoma, and glioblastoma as detected by RNA quantification or immunohistochemistry (49-51). In tumors, high DGKA expression was reported to be associated with cell growth and activation of Ras, mTOR, or HIF1- $\alpha$ signaling pathways and poor survival $(50,51)$. In gastric cancer, however, DGKA expression was found to be modulated by lipid metabolism and high DGKA levels were related with good survival (52). These observations show that DGKA levels can affect many cellular functions depending on tissue or cell type. Comprehensive expression patterns in tumor cells reveal that the interplay with tumor-type specific activated signaling pathways might control DGKA function. Therefore, DGKA was postulated to be a critical signaling node in malignant transformation (51).

At the molecular level, several mechanisms of DGKA regulation have been observed, although which mechanism is active in which cell type is not completely understood. DGKA is located on chromosome 12 encoding several isoforms (Figure 3). Transcription is controlled by at least two functional units, 


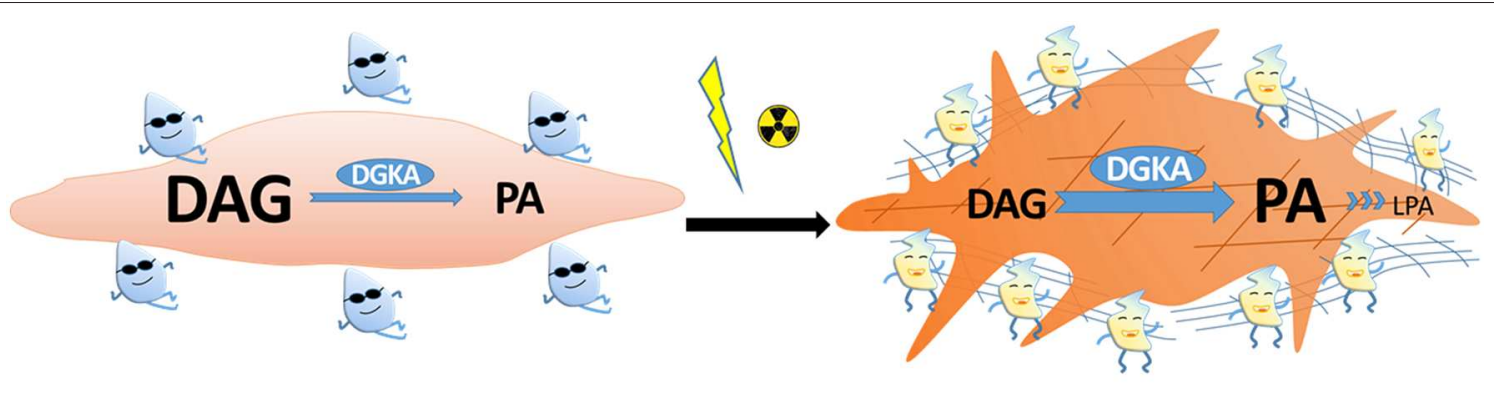

\begin{tabular}{|c|c|c|}
\hline DGKA function & Fibroblast & Myofibroblast \\
\hline Lipid signaling & DAG & PA \\
\hline \multicolumn{3}{|l|}{$\begin{array}{c}\text { Extra cellular } \\
\text { matrix }\end{array}$} \\
\hline \multicolumn{3}{|l|}{$\begin{array}{l}\text { Exosome } \\
\text { secretion }\end{array}$} \\
\hline \multicolumn{3}{|c|}{ Cell cycle regulation? } \\
\hline Immunity & Resting & Activated \\
\hline
\end{tabular}

FIGURE 1 | Scheme of DGKA functions contributing to radiation-induced fibrosis. Induction of DGKA by ionizing irradiation or other extracellular stimuli activates several functions in cells like DAG to PA conversion, lipid signaling, exosome secretion, and production of extracellular matrix proteins. According to cell type, these functions might regulate trans-differentiation to myofibroblasts, activation of immune cells, or pro-fibrotic processes. Interaction of these activated cell types is required for tissue regeneration after irradiation, however, persistence of activated cell states and increased extracellular matrix production will contribute to fibrosis.

a promoter region $5^{\prime}$-upstream of the transcription start site and an intragenic enhancer located in intron 1 which can interact with the promoter as shown by chromatin conformation capture experiments (31). Moreover, differential methylation of the enhancer site modulated induction of DGKA expression after irradiation of fibroblasts. Low DGKA methylation resulted in increased DGKA expression after irradiation and was associated with the development of radiation-induced fibrosis (31). In the patient fibroblasts used in this study, the differential methylation which modulates DGKA expression after irradiation was already present before treatment of cells. A methylation change after irradiation or upregulation of DNA methyltransferase 1 (DNMT1) was not observed (31). Therefore, differential DGKA methylation seems to indicate a stable predisposition of patients for radiation-induced fibrosis. Nevertheless, radiation by itself could change DNA methylation patterns. Although reports on overall changes causing hyper- or hypomethylation are rather contradictory, specific DNA methylation changes have repeatedly been found $(55,56)$ suggesting an epigenetic reprogramming after irradiation which might affect cell fate and therapy outcome.

$D G K A$ expression was up-regulated by exposure to DNA damaging treatments like $\gamma$-irradiation $(31,57)$, UV-exposure or treatment with cytostatic drugs and under hypoxic conditions [summarized in (58)]. Up-regulation was attenuated by silencing or mutating p53 in the investigated cell models suggesting that DGKA-related functions might be part of the comprehensive p53-mediated cellular damage response, as for example after radiotherapy (59). Furthermore, DGKA expression was strongly regulated in different tissues and cell types by activating signaling cascades like those of Src, HIF1- $\alpha$, mTOR, and Ras/ERK (see below) and by binding of pathway-specific transcription factors (TFs). An example in the mouse is the forkhead box O (FoxO) TF in T cells linking the T cell receptor (TCR) activity to DGKA abundance via PI3K activity (60) or the TF Egr2 regulating $\mathrm{T}$ cell anergy (61). Regarding the function of the enhancer region, $D G K A$ expression was stimulated by binding of the radiationinducible transcription factor EGR1 (31). 
A

\section{DGKA RNA expression in normal human tissues}

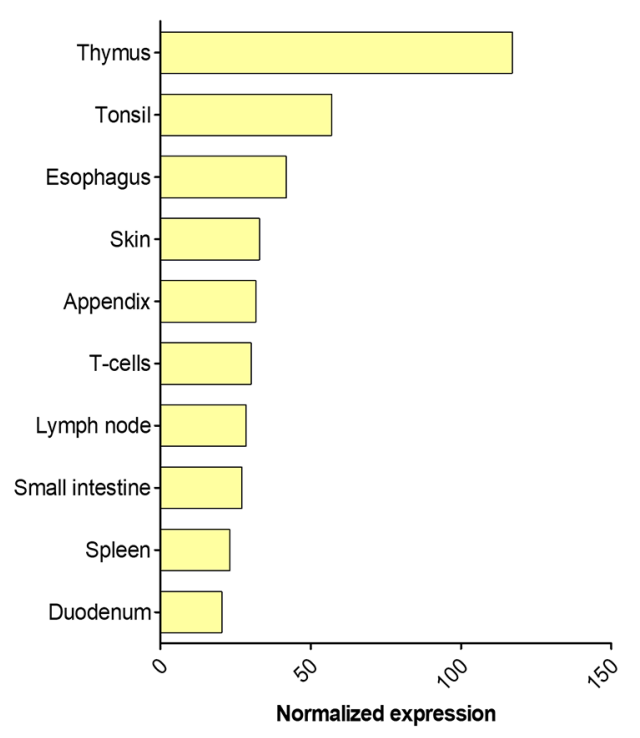

B

DGKA protein expression in specific cell types from normal human tissues

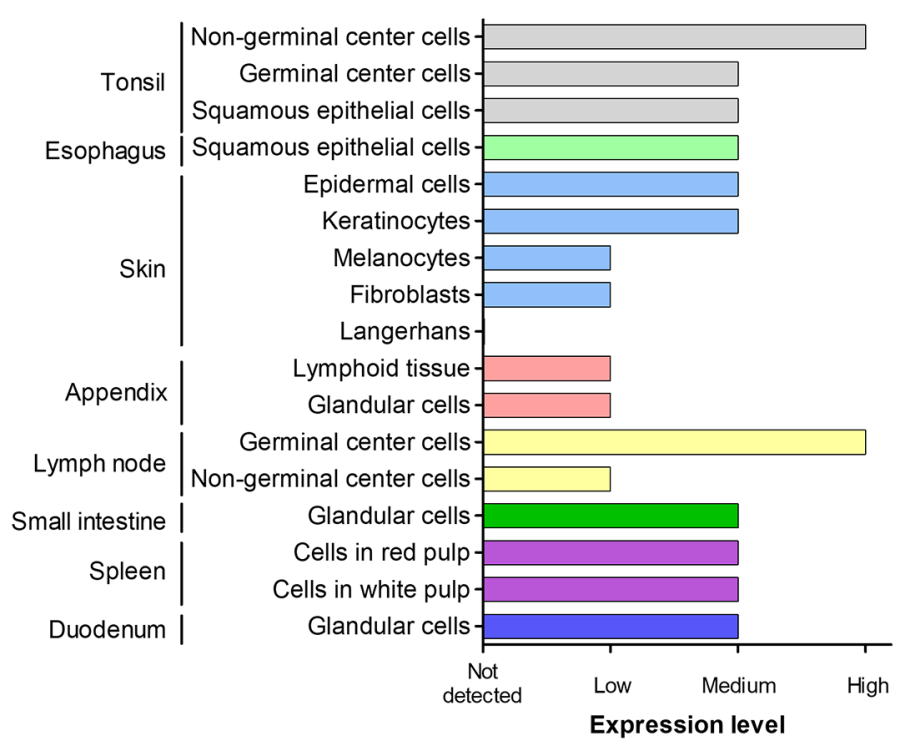

FIGURE 2 | DGKA expression in normal human tissues. (A) The 10 tissues with the highest DGKA RNA expression are shown. Data are derived from a consensus dataset in the Human Protein Atlas (HPA) which combines data from three comprehensive databases (HPA, GTEx, and FANTOM5). (B) DGKA protein expression measured by immunohistochemistry in cell types present in the tissue with the highest RNA expression shown in (A). Protein data for thymus and T cells were not included in the HPA protein database. For details of protein expression, normalization and quantification, see website (https://www.proteinatlas.org/ ENSG00000065357-DGKA/tissue).

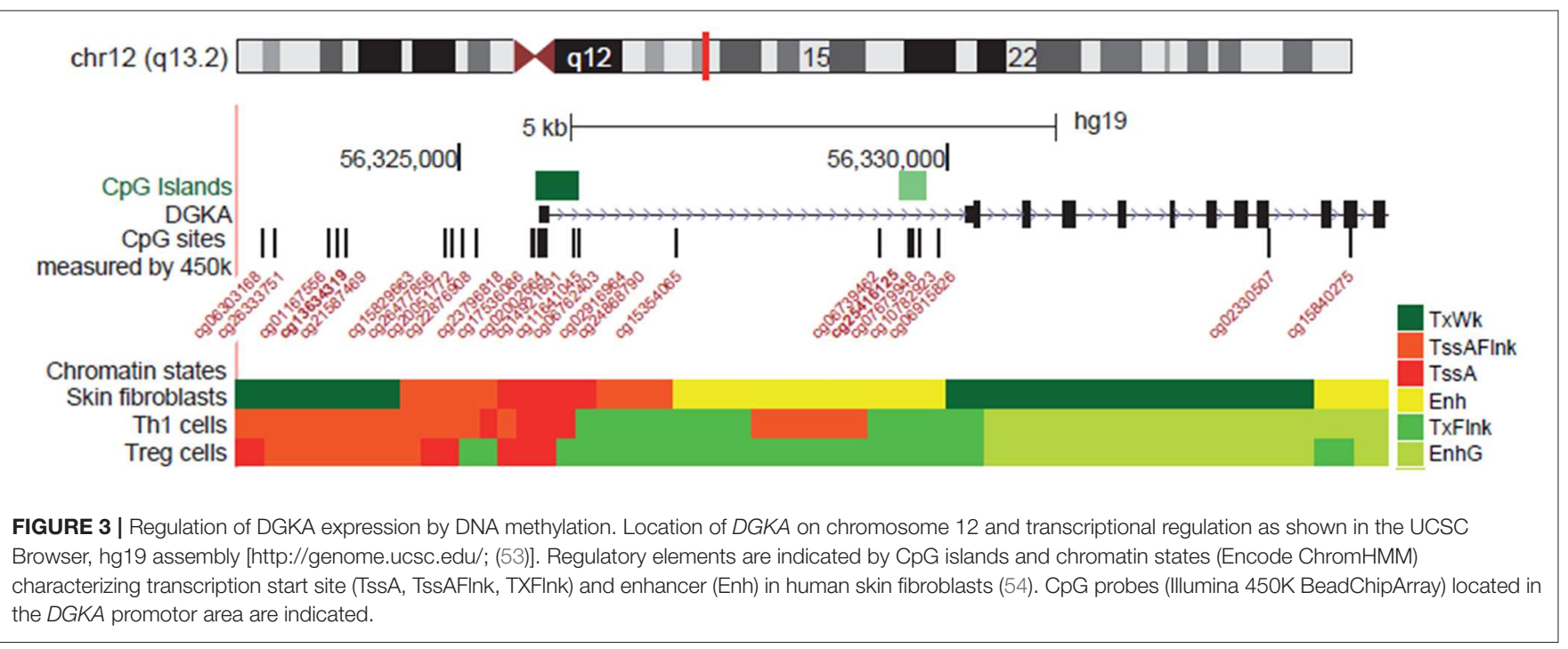

Small RNAs were also involved in the control of DGKA transcripts. Overexpression of miRNA-297 was shown to be cytotoxic to glioblastoma cells but not to normal astrocytes (62). DGKA was the most prominent target of this miRNA. Further evidence comes from the observation that DGKA, when upregulated by hypoxia and its mediator, the heterogeneous nuclear ribonucleoprotein L (HNRNPL), was able to buffer the cytotoxic effects of increased miRNA-297 expression.
Importantly, DGKA controls TF abundance and signaling pathways by itself through the conversion of DAG to PA and regulation of the downstream signaling (33) thus inducing an auto-regulatory loop for a well-balanced equilibrium between these pathways. These findings underpin the importance of maintaining an adequate DGKA level in cells for their proper functioning as it was shown when describing the role of DGKA during $\mathrm{T}$ cell differentiation. Similar to the growth stimulation 
in tumor cells, it is conceivable that differences in DGKA levels affect the cellular amounts of DAG and PA and might contribute to fibroblast activation and migration during wound healing and to the perpetuation of myofibroblast activation in a profibrotic situation.

\section{DGKA-MEDIATED SIGNALING AND LIPID METABOLISM}

The DGK family is involved in lipid metabolism specifically in the conversion of DAG to PA. Both are important intermediates involved in phospholipid metabolism, and they serve as second messengers at the plasma membrane. The DAG/PA ratio is important to maintain cellular homeostasis, and the dysregulation of cellular phospholipids has been implicated in several disorders. For example, radiation-induced free lipid accumulation impairs the normal cellular metabolism via induction of lipoprotein lipase and fatty acid binding protein 4 (FABP4). At the same time, triacylglycerol is also increased resulting in steatosis, progression to inflammation, and fibrosis $(19,63)$.

Overexpressed or activated DGKA results in the generation of PA and activates PA-mediated signaling (Figure 4). This includes mTOR, atypical PKC (aPKC)-RhoGDI, Rab11 family interacting protein 1 (Rab11-FIP1), and phosphatidylinositol-4phosphate 5-kinase (PIP5K) signaling which can lead to fibrosis formation or tumor cell invasion and migration (42, 64-67). In contrast, downregulation or inhibition of DGKA results in the accumulation of DAG, which functions as a second messenger by binding to $\mathrm{C} 1$ domain containing proteins. This binding triggers multiple signaling pathways including RasGRP, classical and novel PKC and PKD, which contribute to T cell anergy and an insulin secretory defect $(33,35,68)$.

Biochemical inhibition or silencing of DGKA was reported to reduce HIF- $1 \alpha$ and mTOR signaling by limiting PA in glioblastoma cells (51). In addition, the cyclic adenosine monophosphate (cAMP) level was observed to be significantly increased in these cells which resulted in downregulation of MTOR transcription. Downregulation of DGKA and its downstream targets HIF- $1 \alpha$ and mTOR resulted in suppression of tumor cell migration and survival. Rescue experiments with mTOR or HIF- $1 \alpha$ restored cell viability. Remarkably, the cytotoxic activity of DGKA attenuation was observed in tumor cells but not in normal cells $(51,69)$. The authors suggested a unique DGKA-PA-posphodiesterase-cAMP-mTOR transcription pathway which would be active besides the lipid signaling DGKA function. Similarly, Chen et al. found a stimulation of the PTEN pathway and the oncogenic Akt/NF$\kappa \mathrm{B}$ activity via $\mathrm{cAMP}$ in esophageal squamous cell carcinoma cells (70) suggesting that, in this way, DGKA might promote cell growth and cancer progression. Both observations were found to be specifically active in malignant cells and make DGKA an exciting target in cancer therapy. These studies further support a unique role of DGKA in cell growth as this activity was independent of the kinase activity. Other DGKs were not reported to be able to substitute the DGKA function in this process $(51,70)$. In L6 myotubes overexpressing the human insulin receptor, DGK inhibition resulted in DAG accumulation, $\mathrm{PKC} \alpha$ activation at the plasma membrane, and reduced glucoseinduced insulin receptor activation (71). Interestingly, DGKA knockdown or inhibition induces a stronger cytotoxicity in cancer cells than in normal cells (69), underlining again that the amount of DGKA might determine its cellular effects. In addition, this observation supports DGKA as a potential therapeutic target for cancer and fibrosis treatment.

DAG and PA are not only acting as second messengers but are also involved in phospholipid metabolism. For example, downregulation of DGKs results in the accumulation of DAG which can cause metabolic disorders because DAG is a precursor for triglycerides and phospholipids such as phosphatidylcholine (PC) and phosphatidylethanolamine (PE) (20). Increased PA levels, in contrast, trigger the generation of lysophosphatidic acid, a lipid involved in many chronic inflammatory diseases including idiopathic pulmonary fibrosis and liver fibrosis (19). Conversion of DAG to PA by DGKs is a demanding task as shown by more than 50 structurally different DAG and PA species in mammals (34). DAG consists of a glycerol backbone which is linked to a saturated and an unsaturated fatty acid which vary in chain length and composition according to the cellular turnover of various phosphatidylinositol (PI) species. Specific DGKs are reported to convert different DAGs (72). For DGKA, this process might be cell type specific as the spectrum of DAG species converted in AKI melanoma cells is not identical to the one observed in normal human dermal fibroblasts $(31,34)$. However, different methods were used for quantification in both cell types.

Finally, it is likely that ionizing radiation which is inducing highly reactive ROS in cells may alter the composition of the DAG spectrum mainly by reacting with the unsaturated part of DAG and PA. This substrate change will cause at least an intermediate imbalance in the DAG to PA ratio with all the possible changes in cellular functions as already described.

\section{RADIATION-INDUCED IMMUNE RESPONSE AND DGKA-MEDIATED T CELL ACTIVATION}

Radiotherapy has been used for decades to eliminate local tumor growth, while different radiation dosage and fractionation also lead to various degrees of injury in surrounding normal tissue because of the induced immune responses (73). Thus, DGKA, as regulated by IR, may be involved in IR-induced immune response through mediating $\mathrm{T}$ cell activation.

During the initial phase of radiation exposure, DNA damage, ROS induction and cell death trigger the release of proinflammatory cytokines (e.g., IL-1, IL-6, IL-10, TGF- $\beta$, TNF$\alpha$, and IFN- $\gamma$ ) and activate immune response $(6,74,75)$. The induction time of pro-inflammatory cytokine secretion can vary from minutes to hours (initial phase) up to days and weeks (early acute inflammatory phase) depending on the radiation dosage and fractionation (15). Lymphocytes and macrophages infiltrate 


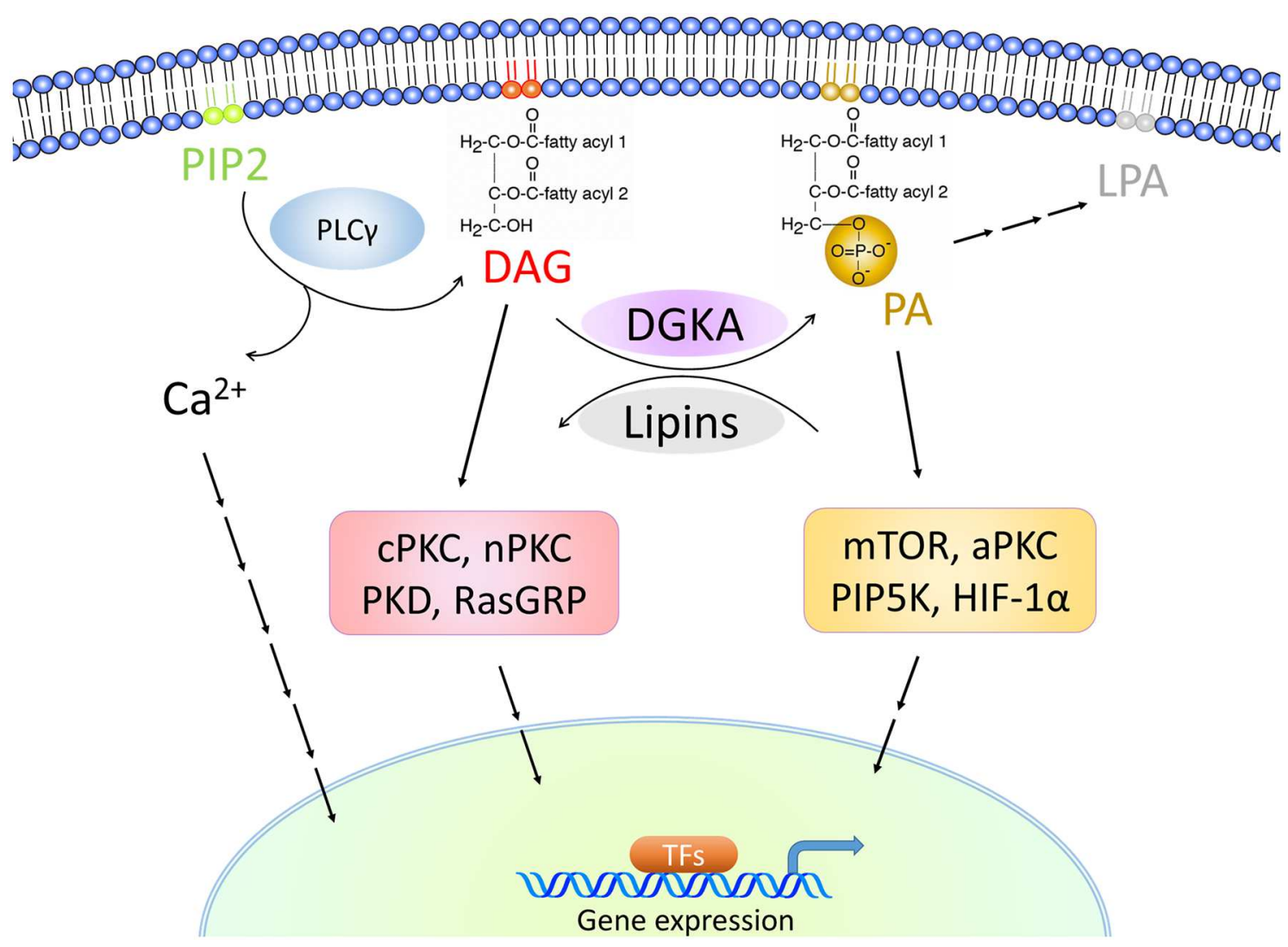

FIGURE 4 | DGKA-associated signaling cascades. DGKA controls the conversion of DAG to PA, two membrane-associated lipid messengers. High DAG levels activate classical PKCs (cPKC) with PKC $\alpha, \beta$ and $\gamma$, novel PKCs (nPKC) with PKC $\delta, \varepsilon, \eta$, and $\theta$, PKD and RasGRP signaling. High PA levels activate mTOR, atypical PKCs (aPKC) with PKC $\zeta$ and PKCl/к, PIP5K, and HIF-1 $\alpha$. The stimulated signaling cascades induce transcription in the nucleus by triggering pathway-specific transcription factors (TFs).

into the injured tissue and induce inflammasome formation. Type I T helper cells (Th1), Th17, and macrophages (M1) are activated and contribute to inflammation around the damaged area. In the late acute inflammatory phase, anti-inflammatory cells including Th2 and regulatory $\mathrm{T}$ cells (Treg) are induced to suppress pro-inflammatory responses. Th2 releases cytokines including IL-3, IL-4, and IL-10 around the injured tissue and triggers fibroblast-to-myofibroblast differentiation along with the accumulation of M2 macrophages (76). During this stage, TGF$\beta$ stimulates the generation of Tregs which further produce TGF- $\beta$ and IL-10 thus contributing to tissue repair and a profibrotic action (77). These alterations continue even throughout the chronic phase of radiation-induced fibrosis. Moreover, radiation-induced accumulation of lipid products such as free fatty acids, triglycerides and DAGs activate the infiltration of macrophages into the damaged tissue and further induce chronic inflammation (7).

Several reviews indicate that DGKs, especially DGKA and DGKZ, play an important role in $\mathrm{T}$ cell activation via termination of DAG signaling $(42,78-80)$, but here we focus on the role of DGKA. In general, $\mathrm{T}$ cell activation requires two signals: the first consists of the interaction of the $\mathrm{T}$ cell receptor (TCR) with foreign antigens bound to the major histocompatibility complex (MHC) on the surface of antigenpresenting cells (APC). This initial signal is responsible for the generation of two phospholipase PLC- $\gamma$-mediated cleavage products, inositol triphosphate (IP3) and DAG. The two second messengers promote the signaling cascades of both the $\mathrm{Ca}^{2+}$ mediated nuclear factor of activated T cells (NFAT) and the Ras/ERK pathway (81). DGKA participates in this step as follows. During initial TCR signaling, $\mathrm{Ca}^{2+}$ generated by PLC$\gamma$ promotes a conformational change of DGKA leading to the activation of its membrane-binding domain, and subsequently to its rapid translocation and binding to the plasma membrane. Membrane-bound DGKA (activated DGKA) metabolizes DAG to PA. However, a further signal is necessary to complete $\mathrm{T}$ cell activation. Co-stimulatory molecules such as CD28, which interact with CD80 on the surface of APC, are essential to fully activate T cells. During this step, PKC $\theta$ is involved in activating NF-кB-mediated IL-2 synthesis (6). The co-stimulatory signals balance the catalytic DGKA activity which is still located at the plasma membrane to avoid that DAG levels become insufficient to activate downstream signaling such as IL-2 secretion. Therefore, over-activated DGKA would result in T cell 
anergy. Co-stimulatory signals and IL-2 also trigger PI3K/AKT activation to further suppress FoxO-dependent DGKA mRNA expression finally creating a feed-back loop limiting DGKA levels and signal intensity $(33,78)$. Thus, DGKA acts as an immunological checkpoint to control the activities of T and NK cells $(82,83)$. A recent study further showed that a lack of DGKA reduced inflammation markers like IL- $1 \beta$ expression in white adipose tissue in mice which were fed with a short-term high-fat diet (84). This suggests that DGKA may be involved in the early immune response also in other tissues.

As a part of the immune response after irradiation, $\mathrm{T}$ and NK cells were shown to be activated and to gain the ability to kill tumor cells after radiotherapy; however, tumors seem to be protected from this cytotoxic activity (85). In renal clear cell carcinoma, for example, the activity of tumor-infiltrating NK cells was inhibited by strong expression of DGKA and insufficient ERK pathway activity. Inhibition of DGKA or reactivation of the ERK pathway reconstituted the anti-tumor activity of $\mathrm{T}$ and NK cells (86). This was also observed in other tumors where inhibition of DGKA and other DGKs restored pro-apoptotic signaling in normal T and NK cells against tumor (83, 87-90). This suggests that DGKA inhibition might be an interesting strategy for tumor therapy. If however, DGKA inhibition results in a similar T and NK cell activation by irradiation in the normal tissue, an increase in tissue damage might be observed which would increase therapeutic side effects. Remarkably, cell toxicity of DGKA inhibitors was found to be lower in normal cells $(51,69)$ making this possibility less probable. In the irradiated healthy tissue, it is therefore assumed that immune cells are infiltrating the damaged tissue, and together with fibroblasts and endothelial cells, induce tissue regeneration. DGKA has been shown to be activated in irradiated fibroblasts of patients with high fibrosis risk (31). This response has not yet been investigated in T cells or in irradiated tissues but it would be interesting to analyze DGKA under both conditions. This would show how the different cell types are interacting during wound healing and whether induced DGKA levels sustainably disturb the DAG balance and induce a prolonged wound healing response which might be pro-fibrotic.

\section{DGKA REGULATES EXOSOME PRODUCTION WHICH CAN ACTIVATE PRO-FIBROTIC FUNCTIONS}

Regeneration of normal tissue after irradiation requires cooperation of multiple cell types like immune cells, fibroblasts or mesenchymal stem cells which are attracted to the injured tissue site and activated for their specific function in the wound. When the wound is closed, attracted cells and induced processes have to be shut down to avoid accumulation of excessive ECM, scars, and on a long-term basis, fibrosis. It is evident that such a process needs multiple intercellular communications. One way could be mediated by membrane trafficking related processes like the release of multivesicular bodies or secretion of exosomes $(47,91)$. Exosomes can transport signaling peptides, proteins or miRNAs depending on cell type and regulated function. They are excreted or internalized by various cell types like stem cells, fibroblasts or lymphocytes (92). These exosome-mediated processes are by far not completely understood but there are some examples that underline the importance of exosomes in fibrogenesis. Exosomes derived from mesenchymal stem cells were reported to activate fibroblast migration and proliferation and to regulate collagen synthesis during wound healing $(92,93)$.

DAGs were suggested to belong to the lipids that contribute to exosome production in $\mathrm{T}$ lymphocytes (94-96). In $\mathrm{T}$ cells, exosomes mainly transport Fas ligand which mediates cytotoxicity and Fas-induced cell death in the targeted area. Membrane-bound DKGA is an essential regulator of the membrane-related process of exosome production as it controls the formation and polarization of mature multivesicular bodies as precursors of exosomes (94). DGKA might drive similar exosome-mediated effects in other cell types. An example is shown in H1299 tumor cells expressing a gain of function p53 mutant (mutp53; R270H; p53R172H). ECM production and the orthogonal branching of collagen, one of the hallmarks of fibrosis, could be substantially impeded by pharmaceutically inhibiting DGKA in these cells (97). In fact, this process was strongly controlled by DGKA-mediated exosome production. A further analysis in mice with mutp53-driven pancreatic cancer revealed this orthogonal ECM characteristic even in the lungs of the animals where it preceded metastasis indicating a potential role of DGKA in ECM production via exosomes (97).

Migration of different cell types to the wound and their perpetuated activation is required for fibrosis to occur. In tumor cells harboring gain-of-function p53 mutations, DGKA increases cell migration and invasion capability. In this process, membrane-bound DGKA generates increased PA levels, thus recruiting $\beta 1$ integrin trafficking and MMP9 secretion to promote cytoskeleton reorganization for protrusion elongation, lamellipodia formation, membrane ruffling, migration, and spreading through the atypical aPKC/Rab-coupling protein (RCP) mediated signaling in epithelial cells (65-67). In mouse embryonic fibroblasts (MEFs), PA-Rac1-mediated cytoskeleton reorganization was mainly promoted by DGKZ or DGKG not by DGKA $(98,99)$. However, DGKA expression in MEFs is relatively low compared to human fibroblasts, so further investigations on DGKA and cell migration in human fibroblasts is needed.

DGKA inhibition or silencing reduce the migration-related membrane processes and finally attenuate migration. Although detection of these processes depends mainly on expression of the mutated p53 protein, data reveal that membrane-bound DGKA is involved in this process, and in a similar way, might participate in wound healing and pro-fibrotic events.

In this context, it should be mentioned that increased collagen production was measured as a pro-fibrotic endpoint in fibroblasts. This was depending on DGKA protein abundance and activity in fibroblasts after $\gamma$-irradiation (31). Whether this in vitro process was accomplished by membrane processes resulting in vesicles or exosomes formation as summarized by Stephens (100) was not analyzed, however increased collagen synthesis and secretion was associated with an increase of mRNA transcription and protein synthesis. This observation underpins the multiple functions DGKA might have depending on the intracellular location of the protein and the abundance in different cell types. 


\section{NUCLEAR LOCALIZATION OF DGKA AND CELL CYCLE REGULATION}

There is evidence that several DGK family members are not only present in the cytosol and cellular membranes but also in the cell nucleus [Table 1; $(112,113)]$. This led to the assumption that there might be a role for DGKs in cell cycle regulation. DGKA nuclear localization was observed in specific cell types such as the human natural killer cell line YT, the mouse lymphocyte cell line CTLL-2 (102) or in rat thymocytes and T-cell-enriched peripheral lymphocytes (103). Furthermore, DGKA was observed to shuttle between the nucleus and the cytoplasm, e.g., Baldanzi et al. showed that upon stimulation of human T lymphocytes, DGKA can exit from the nucleus which is associated with a rapid negative regulation of its enzymatic activity (104). In contrast, serum starvation in the mouse embryo fibroblast cell line $\mathrm{NIH} / 3 \mathrm{~T} 3$ led to the transport of DGKA from the cytoplasm into the nucleus, a process which could be reversed by serum restoration (105).

DGKA is distinctly expressed in different tumor cell types while their normal tissue counterparts are often devoid of its expression; this suggests that it is able to enhance tumor cell proliferation. DGKA is highly expressed in various human hepatocellular carcinoma cell lines (50). Here, the authors observed a significantly enhanced cell proliferation upon overexpression of DGKA. Furthermore, immunohistochemical analyses in tissue samples from patients with hepatocellular carcinoma revealed an association of high DGKA expression and high expression of the cellular proliferation marker Ki-67. DGKA was also strongly expressed in the nuclei of human K562 leukemia cells and was shown to be involved in both changes of the RB phosphorylation status and in the progression of the cell cycle through the G1/S checkpoint (101). These authors used synchronized cells to demonstrate cell cycle phase-dependent

TABLE 1 | DGKA function according to cellular localization.

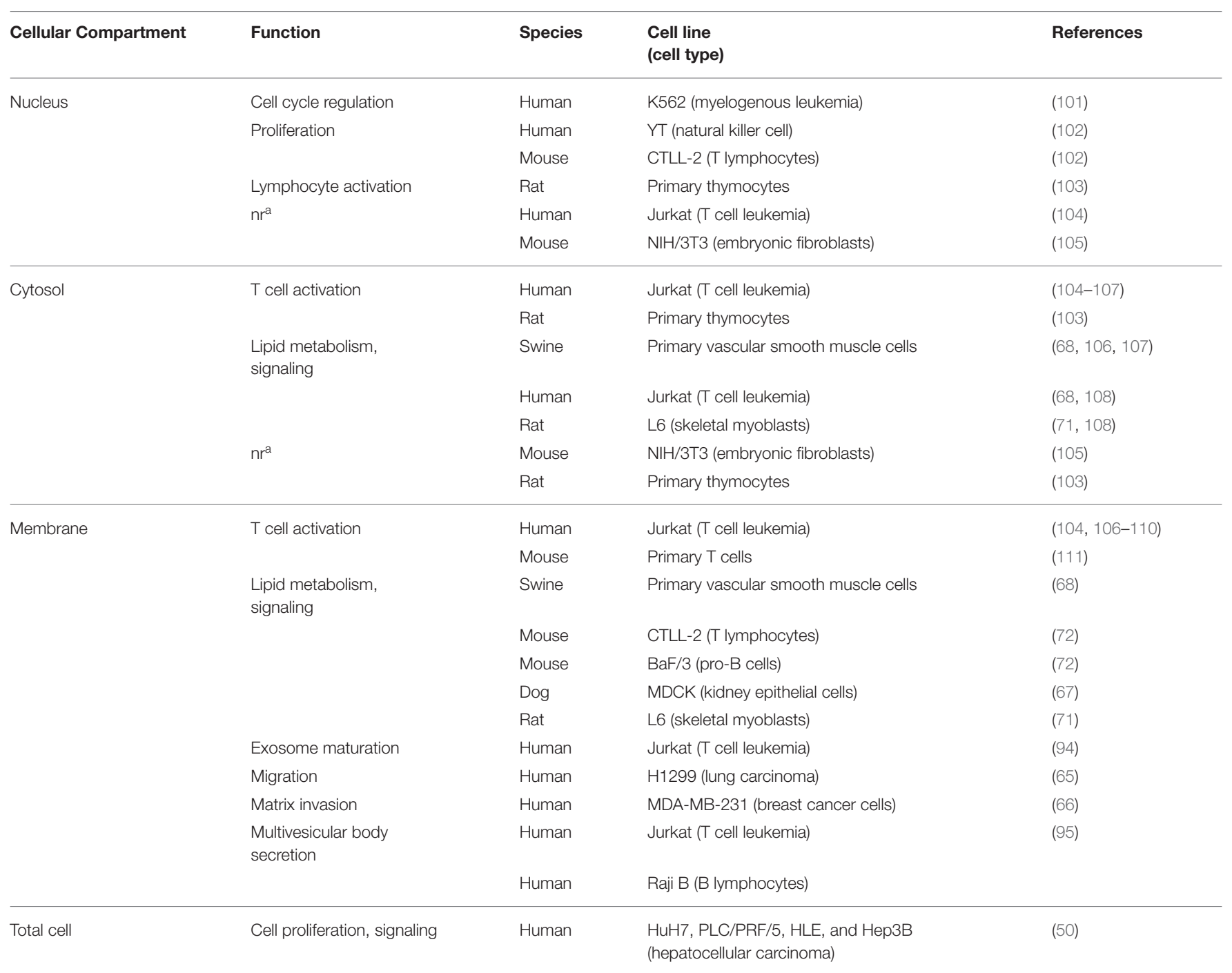

${ }^{a} n r$, not reported. 
DGKA expression, and they applied DGK inhibitors resulting in down-regulation of cell growth and accumulation of cells into G0/G1 phase. Yanagisawa et al. observed DGKA expression in several human melanoma cell lines while normal epidermal melanocytes did not express this protein (49). In addition, they revealed DGKA as a negative regulator of TNF- $\alpha$-induced apoptosis in these tumor cells. Further evidence for an antiapoptotic and proliferation-enhancing activity of DGKA in cancer cells derived from different cancer entities is reported using selective inhibitors of DGKA $(51,69,114)$.

All in all, the above-mentioned studies demonstrate that DGKA (i) is present in the nucleus of different cell types, (ii) is involved in cell cycle regulation, and (iii) has cell-type specificity functions based on its expression levels. Although there is a lack of data on DGKA and cell cycle regulation in fibrosis, it is conceivable that DGKA might play a role in transactivation of resident fibroblasts to replicating active myofibroblasts, the activity of which has to be maintained in fibrotic tissues.

\section{TARGETING OF DGKA BY SMALL COMPOUNDS}

To interfere with the manifold cellular functions of DGKs, compounds were designed to suppress DGK activity. So far, the compounds R59022 and R59949 are described to show a higher selectivity toward type I DGKs including DGKA by binding to the catalytic domain (115). Ritanserin, a serotonin receptor antagonist, and a chemical fragment of it, RF001, were identified to attenuate DGKA function e.g., by increasing the DGKA affinity toward ATP in vitro $(116,117)$. Especially RF001 shows strong effects because it targets both the catalytic domain and the C1 domains of DGKA (117). Most recently, a novel compound, AMB639752, has been identified based on its structural analogy to Ritanserin, R59022 and R59949 (118). The drug shows high specificity for DGKA but does not have the associated activity against the serotonin receptor like the parental drugs. A further compound, $\mathrm{CU}-3$, functions as a competitive ATP inhibitor, but it is unclear why CU-3 has high selectivity for type I DGKs (114). In contrast, a recent study showed that DGKA can be activated when treated with KU-8 (119). Several authors describe that the growth of glioblastoma and other cancers can be impeded with DGKA inhibitors in cell cultures and in xenografts (51, 114, 120). Also AMB639752 is impeding cell migration of MCF7 tumor cells (121). DGKA inhibitors, therefore, offer not only a promising way to manipulate DGKA activity for therapeutic purposes in tumor cells but they might also be helpful to confine a perpetuated wound healing response leading to fibrosis. The current drugs, however, show poor pharmacokinetic data in mice and have considerable off-target effects like targeting the serotonin receptor (116). Still, novel drug screening strategies as those described by Velnati et al. (121) give promise that these limitations can be overcome.

Additional attractive candidates to modulate DGKA levels are epigenetic drugs as they can alter or even reverse aberrant gene expression. Gene expression is organized on different layers by epigenetic mechanisms, especially by DNA methylation and histone modifications (22). As most epigenetic marks in differentiated cells are highly stable and serve as an epigenomic memory (122), a protective epigenomic layout, once established by an epigenetic treatment, could be maintained throughout numerous rounds of cellular replication in fibroblasts (123). As a proof-of-concept for epigenetic therapy, Zeybel et al. (124) halted $\mathrm{CCl}_{4}$-induced liver fibrosis progression in mice with the histone methyltransferase inhibitor 3-deazaneplanocin A (DZNep). DZNep also inhibited myofibroblast transactivation in vitro (124). In a fibroblast model for radiation-induced fibrosis (31), BET-bromodomain inhibitors (JQ1 and PFI-1) suppressed induction of DGKA in bleomycin-treated fibroblasts, reduced histone $\mathrm{H} 3$ lysine 27 acetylation (H3K27ac) at the DGKA enhancer and repressed collagen marker gene expression (125). Here, BET-bromodomain inhibitors altered the epigenetic landscape of fibroblasts, counteracting pro-fibrotic transcriptional events. Of course, the use of epigenetic drugs to alter pro-fibrotic signaling requires further experimental proof, but there is sufficient evidence (126) that altering the chromatin state at the DGKA locus could be a valuable therapeutic approach in fibrosis prevention and might lead to long-lasting, stable protection against radiation-induced fibrogenesis.

A further promising therapeutic approach could be a cotreatment of both disturbed DGKA levels and downstream signaling. In a tentative approach, co-treatment with the DGK inhibitor R59949 and the protein kinase C alpha inhibitor Gö6976 attenuated cell growth and COL1A1 transcription in primary human fibroblasts, indicating great potential to synergistically treat fibrosis development (31). It should however be mentioned here that all anti-fibrotic treatments targeting DGKA either directly or by changing its expression might be demanding, as in case of drug-induced DAG/PA imbalance, other DGK isoforms expressed in cells or further signaling pathways might step in to take over the function of DGKA.

\section{CONCLUSIONS}

Radiotherapy is a highly efficient tool for cancer treatment but the risk of side effects especially radiation-induced fibrosis may considerably restrain therapy outcome by either reducing tumor control or the overall quality of life post-therapy. Therefore, how to prevent fibrosis still requires more detailed studies. Recently, growing evidence indicates that DGKA is a central node regulating numerous cellular functions like immune response, lipid signaling, exosome production and migration as well as cell proliferation by maintaining an adequate DAG to PA balance at cell membranes but also by potential, yet unknown functions in the nucleus. In addition, DGKA expression is inducible by irradiation. Even though the mechanisms of how DGKA contributes, after irradiation of cells, to the pro-fibrotic processes of myofibroblast transactivation and production of ECM are still not fully elucidated, there is strong evidence that DGKA is activated after irradiation and that it has many competences to play a central function in fibrosis development when disturbed by irradiation. Inhibitors 
that target DGKA function and protein levels either by direct interaction with the protein, by addressing its epigenetic control or by modulating DAG-dependent signaling might therefore offer novel therapeutic avenues to prevent or attenuate radiotherapy-induced fibrosis.

\section{AUTHOR CONTRIBUTIONS}

All authors were involved in literature search, drafting the manuscript and designing the figures, developed the concept and aim of the review, and approved the final manuscript.

\section{REFERENCES}

1. Thompson MK, Poortmans P, Chalmers AJ, Faivre-Finn C, Hall E, Huddart RA, et al. Practice-changing radiation therapy trials for the treatment of cancer: where are we 150 years after the birth of Marie Curie? Br J Cancer. (2018) 119:389-407. doi: 10.1038/s41416-018-0201-z

2. De Ruysscher D, Niedermann G, Burnet NG, Siva S, Lee AWM, Hegi-Johnson F. Radiotherapy toxicity. Nat Rev Dis Primers. (2019) 5:13. doi: 10.1038/s41572-019-0064-5

3. Pavlopoulou A, Bagos PG, Koutsandrea V, Georgakilas AG. Molecular determinants of radiosensitivity in normal and tumor tissue: a bioinformatic approach. Cancer Lett. (2017) 403:37-47. doi: 10.1016/j.canlet.2017. 05.023

4. Schafer MJ, Haak AJ, Tschumperlin DJ, LeBrasseur NK. Targeting senescent cells in fibrosis: pathology, paradox, and practical considerations. Curr Rheumatol Rep. (2018) 20:3. doi: 10.1007/s11926-018-0712-x

5. Jain V, Berman AT. Radiation pneumonitis: old problem, new tricks. Cancers. (2018) 10:222. doi: 10.3390/cancers10070222

6. Wirsdorfer F, Jendrossek V. The role of lymphocytes in radiotherapyinduced adverse late effects in the lung. Front Immunol. (2016) 7:591. doi: 10.3389/fimmu.2016.00591

7. Gowda SSN, Raviraj R, Nagarajan D, Zhao W. Radiation-induced lung injury: impact on macrophage dysregulation and lipid alteration - a review. Immunopharmacol Immunotoxicol. (2019) 41:370-9. doi: 10.1080/08923973.2018.1533025

8. Giuranno L, Ient J, De Ruysscher D, Vooijs MA. Radiation-induced lung injury (RILI). Front Oncol. (2019) 9:877. doi: 10.3389/fonc.2019.00877

9. Zanoni M, Cortesi M, Zamagni A, Tesei A. The role of mesenchymal stem cells in radiation-induced lung fibrosis. Int J Mol Sci. (2019) 20:3876. doi: 10.3390/ijms20163876

10. Baudelet M, Van den Steen L, Tomassen P, Bonte K, Deron P, Huvenne W, et al. Very late xerostomia, dysphagia, and neck fibrosis after head and neck radiotherapy. Head Neck. (2019) 41:3594-603. doi: 10.1002/hed.25880

11. Pez M, Keller A, Welzel G, Abo-Madyan Y, Ehmann M, Tuschy B, et al. Longterm outcome after intraoperative radiotherapy as a boost in breast cancer. Strahlenther Onkol. (2019) 196:349-55. doi: 10.1007/s00066-019-01525-7

12. Straub JM, New J, Hamilton CD, Lominska C, Shnayder Y, Thomas SM. Radiation-induced fibrosis: mechanisms and implications for therapy. $J$ Cancer Res Clin Oncol. (2015) 141:1985-94. doi: 10.1007/s00432-015-1974-6

13. Ramachandran P, Dobie R, Wilson-Kanamori JR, Dora EF, Henderson BEP, Luu NT, et al. Resolving the fibrotic niche of human liver cirrhosis at single-cell level. Nature. (2019) 575:512-8. doi: 10.1038/s41586-019-1631-3

14. Weiskirchen R, Weiskirchen S, Tacke F. Recent advances in understanding liver fibrosis: bridging basic science and individualized treatment concepts. F1000Res. (2018) 7:F1000. doi: 10.12688/f1000research.14841.1

15. Ejaz A, Greenberger JS, Rubin PJ. Understanding the mechanism of radiation induced fibrosis and therapy options. Pharmacol Ther. (2019) 204:107399. doi: 10.1016/j.pharmthera.2019.107399

16. Kwon YK, Ha IJ, Bae HW, Jang WG, Yun HJ, Kim SR, et al. Dose-dependent metabolic alterations in human cells exposed to gamma irradiation. PLoS ONE. (2014) 9:e113573. doi: 10.1371/journal.pone.0113573

\section{FUNDING}

This work was supported by the Deutsche Krebshilfe, Grant No. 70112734.

\section{ACKNOWLEDGMENTS}

We thank Carsten Herskind and Marlon R. Veldwijk for critically reading the manuscript and helpful suggestions. We are grateful to Clarissa Gerhäuser for supportive discussions and graphical assistance.

17. $\mathrm{Xu} Y$, Wang $\mathrm{D}$, Wang $\mathrm{Z}$. Lipid generation and signaling in ovarian cancer. Cancer Treat Res. (2009) 149:241-67. doi: 10.1007/978-0-387-98094-2_12

18. Rancoule C, Espenel S, Trone JC, Langrand-Escure J, Vallard A, RehailiaBlanchard A, et al. Lysophosphatidic acid (LPA) as a pro-fibrotic and prooncogenic factor: a pivotal target to improve the radiotherapy therapeutic index. Oncotarget. (2017) 8:43543-54. doi: 10.18632/oncotarget.16672

19. Magkrioti C, Galaris A, Kanellopoulou P, Stylianaki EA, Kaffe E, Aidinis V. Autotaxin and chronic inflammatory diseases. J Autoimmun. (2019) 104:102327. doi: 10.1016/j.jaut.2019.102327

20. Itani SI, Ruderman NB, Schmieder F, Boden G. Lipid-induced insulin resistance in human muscle is associated with changes in diacylglycerol, protein kinase C, and IkappaB-alpha. Diabetes. (2002) 51:2005-11. doi: 10.2337/diabetes.51.7.2005

21. Deng W, Shuyu E, Tsukahara R, Valentine WJ, Durgam G, Gududuru V, et al. The lysophosphatidic acid type 2 receptor is required for protection against radiation-induced intestinal injury. Gastroenterology. (2007) 132:183451. doi: 10.1053/j.gastro.2007.03.038

22. Weigel C, Schmezer P, Plass C, Popanda O. Epigenetics in radiation-induced fibrosis. Oncogene. (2015) 34:2145-55. doi: 10.1038/onc.2014.145

23. Ghosh K, O’Neil K, Capell BC. Histone modifiers: dynamic regulators of the cutaneous transcriptome. J Dermatol Sci. (2018) 89:226-32. doi: 10.1016/j.jdermsci.2017.12.006

24. Mori R, Tanaka K, Shimokawa I. Identification and functional analysis of inflammation-related miRNAs in skin wound repair. Dev Growth Differ. (2018) 60:306-15. doi: 10.1111/dgd.12542

25. Lu L, Sun C, Su Q, Wang Y, Li J, Guo Z, et al. Radiationinduced lung injury: latest molecular developments, therapeutic approaches, and clinical guidance. Clin Exp Med. (2019) 19:417-26. doi: 10.1007/s10238-019-00571-w

26. Wang B, Wei J, Meng L, Wang $\mathrm{H}$, Qu C, Chen $\mathrm{X}$, et al. Advances in pathogenic mechanisms and management of radiation-induced fibrosis. Biomed Pharmacother. (2020) 121:109560. doi: 10.1016/j.biopha.2019.109560

27. Wang LP, Wang YW, Wang BZ, Sun GM, Wang XY, Xu JL. Expression of interleukin-17A in lung tissues of irradiated mice and the influence of dexamethasone. Sci World J. (2014) 2014:251067. doi: 10.1155/2014/251067

28. Bickelhaupt S, Erbel C, Timke C, Wirkner U, Dadrich M, Flechsig $\mathrm{P}$, et al. Effects of CTGF blockade on attenuation and reversal of radiation-induced pulmonary fibrosis. J Natl Cancer Inst. (2017) 109:djw339. doi: 10.1093/jnci/djw339

29. Luangmonkong T, Suriguga S, Bigaeva E, Boersema M, Oosterhuis D, de Jong KP, et al. Evaluating the antifibrotic potency of galunisertib in a human ex vivo model of liver fibrosis. Br J Pharmacol. (2017) 174:31073117. doi: 10.1111/bph.13945

30. Sperk E, Welzel G, Keller A, Kraus-Tiefenbacher U, Gerhardt A, Sutterlin $\mathrm{M}$, et al. Late radiation toxicity after intraoperative radiotherapy (IORT) for breast cancer: results from the randomized phase III trial TARGIT A. Breast Cancer Res Treat. (2012) 135:253-60. doi: 10.1007/s10549-012-2168-4

31. Weigel C, Veldwijk MR, Oakes CC, Seibold P, Slynko A, Liesenfeld DB, et al. Epigenetic regulation of diacylglycerol kinase alpha promotes radiationinduced fibrosis. Nat Commun. (2016) 7:10893. doi: 10.1038/ncomms10893 
32. LENT SOMA scales for all anatomic sites. Int J Radiat Oncol Biol Phys. (1995). 31:1049-91. doi: 10.1016/0360-3016(95)90159-0

33. Merida I, Arranz-Nicolas J, Torres-Ayuso P, Avila-Flores A. Diacylglycerol kinase malfunction in human disease and the search for specific inhibitors. Handb Exp Pharmacol. (2020) 259:133-62. doi: 10.1007/164_2019_221

34. Sakane F, Mizuno S, Takahashi D, Sakai H. Where do substrates of diacylglycerol kinases come from? Diacylglycerol kinases utilize diacylglycerol species supplied from phosphatidylinositol turnover-independent pathways. Adv Biol Regul. (2018) 67:1018. doi: 10.1016/j.jbior.2017.09.003

35. Massart J, Zierath JR. Role of diacylglycerol kinases in glucose and energy homeostasis. Trends Endocrinol Metab. (2019) 30:603-17. doi: 10.1016/j.tem.2019.06.003

36. Merida I, Arranz-Nicolas J, Rodriguez-Rodriguez C, Avila-Flores A. Diacylglycerol kinase control of protein kinase C. Biochem J. (2019) 476:1205-19. doi: 10.1042/BCJ20180620

37. Purow B. Molecular pathways: targeting diacylglycerol kinase alpha in cancer. Clin Cancer Res. (2015) 21:500812. doi: $10.1158 / 1078-0432 . C C R-15-0413$

38. Stace CL, Ktistakis NT. Phosphatidic acid- and phosphatidylserinebinding proteins. Biochim Biophys Acta. (2006) 1761:91326. doi: 10.1016/j.bbalip.2006.03.006

39. Almena M, Merida I. Shaping up the membrane: diacylglycerol coordinates spatial orientation of signaling. Trends Biochem Sci. (2011) 36:593603. doi: 10.1016/j.tibs.2011.06.005

40. Topham MK, Prescott SM. Diacylglycerol kinase zeta regulates Ras activation by a novel mechanism. J Cell Biol. (2001) 152:1135-43. doi: 10.1083/jcb.152.6.1135

41. Carrasco S, Merida I. Diacylglycerol, when simplicity becomes complex. Trends Biochem Sci. (2007) 32:27-36. doi: 10.1016/j.tibs.2006.11.004

42. Chen SS, Hu Z, Zhong XP. Diacylglycerol kinases in $\mathrm{T}$ cell tolerance and effector function. Front Cell Dev Biol. (2016) 4:130. doi: 10.3389/fcell.2016.00130

43. Merida I, Avila-Flores A, Merino E. Diacylglycerol kinases: at the hub of cell signalling. Biochem J. (2008) 409:1-18. doi: 10.1042/BJ20071040

44. Labesse G, Douguet D, Assairi L, Gilles AM. Diacylglyceride kinases, sphingosine kinases and NAD kinases: distant relatives of 6-phosphofructokinases. Trends Biochem Sci. (2002) 27:2735. doi: 10.1016/s0968-0004(02)02093-5

45. Shulga YV, Topham MK, Epand RM. Regulation and functions of diacylglycerol kinases. Chem Rev. (2011) 111:6186208. doi: $10.1021 / \mathrm{cr} 1004106$

46. Shirai Y, Saito N. Diacylglycerol kinase as a possible therapeutic target for neuronal diseases. J Biomed Sci. (2014) 21:28. doi: 10.1186/1423-0127-21-28

47. Xie S, Naslavsky N, Caplan S. Diacylglycerol kinases in membrane trafficking. Cell Logist. (2015) 5:e1078431. doi: 10.1080/21592799.2015.1078431

48. Ma Q, Gabelli SB, Raben DM. Diacylglycerol kinases: relationship to other lipid kinases. Adv Biol Regul. (2019) 71:104-110. doi: 10.1016/j.jbior.2018.09.014

49. Yanagisawa K, Yasuda S, Kai M, Imai S, Yamada K, Yamashita T, et al. Diacylglycerol kinase alpha suppresses tumor necrosis factor-alpha-induced apoptosis of human melanoma cells through NF-kappaB activation. Biochim Biophys Acta. (2007) 1771:462-74. doi: 10.1016/j.bbalip.2006.12.008

50. Takeishi K, Taketomi A, Shirabe K, Toshima T, Motomura T, Ikegami $\mathrm{T}$, et al. Diacylglycerol kinase alpha enhances hepatocellular carcinoma progression by activation of Ras-Raf-MEK-ERK pathway. J Hepatol. (2012) 57:77-83. doi: 10.1016/j.jhep.2012.02.026

51. Dominguez CL, Floyd DH, Xiao A, Mullins GR, Kefas BA, Xin W, et al. Diacylglycerol kinase alpha is a critical signaling node and novel therapeutic target in glioblastoma and other cancers. Cancer Discov. (2013) 3:78297. doi: 10.1158/2159-8290.CD-12-0215

52. Kong Y, Zheng Y, Jia Y, Li P, Wang Y. Decreased LIPF expression is correlated with DGKA and predicts poor outcome of gastric cancer. Oncol Rep. (2016) 36:1852-60. doi: 10.3892/or.2016.4989

53. Kent WJ, Sugnet CW, Furey TS, Roskin KM, Pringle TH, Zahler AM, et al. The human genome browser at UCSC. Genome Res. (2002) 12:9961006. doi: $10.1101 /$ gr.229102
54. Rosenbloom KR, Sloan CA, Malladi VS, Dreszer TR, Learned K, Kirkup VM, et al. ENCODE data in the UCSC genome browser: year 5 update. Nucleic Acids Res. (2013) 41:D56-63. doi: 10.1093/nar/gks1172

55. Kuhmann C, Weichenhan D, Rehli M, Plass C, Schmezer P, Popanda O. DNA methylation changes in cells regrowing after fractioned ionizing radiation. Radiother Oncol. (2011) 101:116-21. doi: 10.1016/j.radonc.2011.05.048

56. Zielske SP. Epigenetic DNA methylation in radiation biology: on the field or on the sidelines? J Cell Biochem. (2015) 116:212-7. doi: 10.1002/jcb.24959

57. Heinloth AN, Shackelford RE, Innes CL, Bennett L, Li L, Amin RP, et al. Identification of distinct and common gene expression changes after oxidative stress and gamma and ultraviolet radiation. Mol Carcinog. (2003) 37:65-82. doi: $10.1002 / \mathrm{mc} .10122$

58. Merida I, Avila-Flores A, Garcia J, Merino E, Almena M, Torres-Ayuso P. Diacylglycerol kinase alpha, from negative modulation of $\mathrm{T}$ cell activation to control of cancer progression. Adv Enzyme Regul. (2009) 49:17488. doi: 10.1016/j.advenzreg.2009.01.003

59. Kerley-Hamilton JS, Pike AM, Li N, DiRenzo J, Spinella MJ. A p53dominant transcriptional response to cisplatin in testicular germ cell tumor-derived human embryonal carcinoma. Oncogene. (2005) 24:6090100. doi: 10.1038/sj.onc. 1208755

60. Martinez-Moreno M, Garcia-Lievana J, Soutar D, Torres-Ayuso $\mathrm{P}$, Andrada E, Zhong XP, et al. FoxO-dependent regulation of diacylglycerol kinase alpha gene expression. Mol Cell Biol. (2012) 32:4168-80. doi: 10.1128/MCB.00654-12

61. Zheng Y, Zha Y, Driessens G, Locke F, Gajewski TF. Transcriptional regulator early growth response gene 2 (Egr2) is required for T cell anergy in vitro and in vivo. J Exp Med. (2012) 209:2157-63. doi: 10.1084/jem.20120342

62. Kefas B, Floyd DH, Comeau L, Frisbee A, Dominguez C, Dipierro CG, et al. A miR-297/hypoxia/DGK-alpha axis regulating glioblastoma survival. Neuro Oncol. (2013) 15:1652-63. doi: 10.1093/neuonc/not118

63. Gorden DL, Ivanova PT, Myers DS, McIntyre JO, VanSaun MN, Wright JK, et al. Increased diacylglycerols characterize hepatic lipid changes in progression of human nonalcoholic fatty liver disease; comparison to a murine model. PLoS ONE. (2011) 6:e22775. doi: 10.1371/journal.pone.0022775

64. Shende $\mathrm{P}$, Xu L, Morandi C, Pentassuglia L, Heim P, Lebboukh $\mathrm{S}$, et al. Cardiac mTOR complex 2 preserves ventricular function in pressure-overload hypertrophy. Cardiovasc Res. (2016) 109:103-14. doi: 10.1093/cvr/cvv252

65. Rainero E, Caswell PT, Muller PA, Grindlay J, McCaffrey MW, Zhang $\mathrm{Q}$, et al. Diacylglycerol kinase alpha controls RCP-dependent integrin trafficking to promote invasive migration. J Cell Biol. (2012) 196:27795. doi: $10.1083 /$ jcb.201109112

66. Rainero E, Cianflone C, Porporato PE, Chianale F, Malacarne V, Bettio V, et al. The diacylglycerol kinase alpha/atypical PKC/betal integrin pathway in SDF-1alpha mammary carcinoma invasiveness. PLoS ONE. (2014) 9:e97144. doi: 10.1371/journal.pone.0097144

67. Chianale F, Rainero E, Cianflone C, Bettio V, Pighini A, Porporato PE, et al. Diacylglycerol kinase alpha mediates HGF-induced Rac activation membrane ruffling by regulating atypical PKC RhoGDI. Proc Natl Acad Sci USA. (2010) 107:4182-7. doi: 10.1073/pnas.0908326107

68. Du X, Jiang Y, Qian W, Lu X, Walsh JP. Fatty acids inhibit growth-factorinduced diacylglycerol kinase alpha activation in vascular smooth-muscle cells. Biochem J. (2001) 357(Pt 1):275-82. doi: 10.1042/0264-6021:3570275

69. Yamaki A, Akiyama R, Murakami C, Takao S, Murakami Y, Mizuno S, et al. Diacylglycerol kinase alpha-selective inhibitors induce apoptosis and reduce viability of melanoma and several other cancer cell lines. J Cell Biochem. (2019) 120:10043-56. doi: 10.1002/jcb.28288

70. Chen J, Zhang W, Wang Y, Zhao D, Wu M, Fan J, et al. The diacylglycerol kinase alpha $(\mathrm{DG} \alpha) / \mathrm{Akt} / \mathrm{NF}-\kappa \mathrm{B}$ feedforward loop promotes esophageal squamous cell carcinoma (ESCC) progression via FAKdependent and FAK-independent manner. Oncogene. (2019) 38:253350. doi: 10.1038/s41388-018-0604-6

71. Miele C, Paturzo F, Teperino R, Sakane F, Fiory F, Oriente F, et al. Glucose regulates diacylglycerol intracellular levels and protein kinase $\mathrm{C}$ activity by modulating diacylglycerol kinase subcellular localization. J Biol Chem. (2007) 282:31835-43. doi: 10.1074/jbc.M702481200 
72. Cipres A, Carrasco S, Merino E, Diaz E, Krishna UM, Falck JR, et al. Regulation of diacylglycerol kinase alpha by phosphoinositide 3-kinase lipid products. J Biol Chem. (2003) 278:35629-35. doi: 10.1074/jbc.M305635200

73. Herskind C, Wenz F, Giordano FA. Immunotherapy combined with large fractions of radiotherapy: stereotactic radiosurgery for brain metastasesimplications for intraoperative radiotherapy after resection. Front Oncol. (2017) 7:147. doi: 10.3389/fonc.2017.00147

74. McBride WH, Chiang CS, Olson JL, Wang CC, Hong JH, Pajonk F, et al. A sense of danger from radiation. Radiat Res. (2004) 162:119. doi: $10.1667 / \mathrm{rr} 3196$

75. Najafi M, Motevaseli E, Shirazi A, Geraily G, Rezaeyan A, Norouzi F, et al. Mechanisms of inflammatory responses to radiation and normal tissues toxicity: clinical implications. Int J Radiat Biol. (2018) 94:33556. doi: 10.1080/09553002.2018.1440092

76. Ding NH, Li JJ, Sun LQ. Molecular mechanisms and treatment of radiation-induced lung fibrosis. Curr Drug Targets. (2013) 14:134756. doi: 10.2174/13894501113149990198

77. Das A, Sinha M, Datta S, Abas M, Chaffee S, Sen CK, et al. Monocyte and macrophage plasticity in tissue repair and regeneration. Am J Pathol. (2015) 185:2596-606. doi: 10.1016/j.ajpath.2015.06.001

78. Merida I, Andrada E, Gharbi SI, Avila-Flores A. Redundant and specialized roles for diacylglycerol kinases alpha and zeta in the control of $\mathrm{T}$ cell functions. Sci Signal. (2015) 8:re6. doi: 10.1126/scisignal.aaa0974

79. Joshi RP, Koretzky GA. Diacylglycerol kinases: regulated controllers of T cell activation, function, and development. Int J Mol Sci. (2013) 14:664973. doi: 10.3390/ijms14046649

80. Zhong XP, Guo R, Zhou H, Liu C, Wan CK. Diacylglycerol kinases in immune cell function and self-tolerance. Immunol Rev. (2008) 224:24964. doi: 10.1111/j.1600-065X.2008.00647.x

81. Krishna S, Zhong XP. Regulation of lipid signaling by diacylglycerol kinases during $\mathrm{T}$ cell development and function. Front Immunol. (2013) 4:178. doi: 10.3389/fimmu.2013.00178

82. Sadreddini S, Baradaran B, Aghebati-Maleki A, Sadreddini S, Shanehbandi D, Fotouhi A, et al. Immune checkpoint blockade opens a new way to cancer immunotherapy. J Cell Physiol. (2019) 234:8541-8549. doi: 10.1002/jcp.27816

83. Noessner E. DGK-alpha: a checkpoint in cancer-mediated immunoinhibition and target for immunotherapy. Front Cell Dev Biol. (2017) 5:16. doi: 10.3389/fcell.2017.00016

84. Nascimento EBM, Manneras-Holm L, Chibalin AV, Bjornholm M, Zierath JR. Diacylglycerol kinase alpha deficiency alters inflammation markers in adipose tissue in response to a high-fat diet. J Lipid Res. (2018) 59:273282. doi: 10.1194/jlr.M079517

85. Abbas AK, Lichtman AH, Pillai S, Baker DL, Baker A. Cellular and Molecular Immunology. 9th ed. Philadelphia, PA. Elsevier (2018). p. 565.

86. Prinz PU, Mendler AN, Brech D, Masouris I, Oberneder R, Noessner E. NKcell dysfunction in human renal carcinoma reveals diacylglycerol kinase as key regulator and target for therapeutic intervention. Int J Cancer. (2014) 135:1832-41. doi: 10.1002/ijc.28837

87. Riese MJ, Wang LC, Moon EK, Joshi RP, Ranganathan A, June $\mathrm{CH}$, et al. Enhanced effector responses in activated CD8+ $\mathrm{T}$ cells deficient in diacylglycerol kinases. Cancer Res. (2013) 73:3566-77. doi: 10.1158/0008-5472.CAN-12-3874

88. Riese MJ, Moon EK, Johnson BD, Albelda SM. Diacylglycerol kinases (DGKs): novel targets for improving T cell activity in cancer. Front Cell Dev Biol. (2016) 4:108. doi: 10.3389/fcell.2016.00108

89. Riese MJ, Grewal J, Das J, Zou T, Patil V, Chakraborty AK, et al. Decreased diacylglycerol metabolism enhances ERK activation and augments CD8+ $\mathrm{T}$ cell functional responses. J Biol Chem. (2011) 286:5254-65. doi: 10.1074/jbc.M110.171884

90. Ruffo E, Malacarne V, Larsen SE, Das R, Patrussi L, Wulfing C, et al. Inhibition of diacylglycerol kinase alpha restores restimulation-induced cell death and reduces immunopathology in XLP-1. Sci Transl Med. (2016) 8:321 ra7. doi: 10.1126/scitranslmed.aad1565

91. Colletti M, Galardi A, De Santis M, Guidelli GM, Di Giannatale A, Di Luigi L, et al. Exosomes in systemic sclerosis: messengers between immune. Vascular and Fibrotic Components? Int J Mol Sci. (2019) 20:4337. doi: 10.3390/ijms20184337
92. Hu L, Wang J, Zhou X, Xiong Z, Zhao J, Yu R, et al. Exosomes derived from human adipose mensenchymal stem cells accelerates cutaneous wound healing via optimizing the characteristics of fibroblasts. Sci Rep. (2016) 6:32993. doi: 10.1038/srep32993

93. Zhang J, Guan J, Niu X, Hu G, Guo S, Li Q, et al. Exosomes released from human induced pluripotent stem cells-derived MSCs facilitate cutaneous wound healing by promoting collagen synthesis and angiogenesis. J Transl Med. (2015) 13:49. doi: 10.1186/s12967-015-0417-0

94. Alonso R, Mazzeo C, Rodriguez MC, Marsh M, Fraile-Ramos A, Calvo V, et al. Diacylglycerol kinase alpha regulates the formation and polarisation of mature multivesicular bodies involved in the secretion of Fas ligandcontaining exosomes in T lymphocytes. Cell Death Differ. (2011) 18:116173. doi: $10.1038 /$ cdd.2010.184

95. Mazzeo C, Calvo V, Alonso R, Merida I, Izquierdo M. Protein kinase $\mathrm{D} 1 / 2$ is involved in the maturation of multivesicular bodies and secretion of exosomes in T and B lymphocytes. Cell Death Differ. (2016) 23:99109. doi: $10.1038 /$ cdd.2015.72

96. Alonso R, Rodriguez MC, Pindado J, Merino E, Merida I, Izquierdo M. Diacylglycerol kinase alpha regulates the secretion of lethal exosomes bearing Fas ligand during activation-induced cell death of T lymphocytes. J Biol Chem. (2005) 280:28439-50. doi: 10.1074/jbc.M501112200

97. Novo D, Heath N, Mitchell L, Caligiuri G, MacFarlane A, Reijmer D, et al. Mutant p53s generate pro-invasive niches by influencing exosome podocalyxin levels. Nat Commun. (2018) 9:5069. doi: 10.1038/s41467-018-07339-y

98. Abramovici H, Mojtabaie P, Parks RJ, Zhong XP, Koretzky GA, Topham MK, et al. Diacylglycerol kinase zeta regulates actin cytoskeleton reorganization through dissociation of Rac1 from RhoGDI. Mol Biol Cell. (2009) 20:2049_ 59. doi: 10.1091/mbc.E07-12-1248

99. Tsushima S, Kai M, Yamada K, Imai S, Houkin K, Kanoh H, et al. Diacylglycerol kinase gamma serves as an upstream suppressor of Rac1 and lamellipodium formation. J Biol Chem. (2004) 279:2860313. doi: 10.1074/jbc.M314031200

100. Stephens DJ. Cell biology: collagen secretion explained. Nature. (2012) 482:474-5. doi: 10.1038/482474a

101. Poli A, Fiume R, Baldanzi G, Capello D, Ratti S, Gesi M, et al. Nuclear localization of diacylglycerol kinase alpha in K562 cells is involved in cell cycle progression. J Cell Physiol. (2017) 232:2550-7. doi: 10.1002/jcp.25642

102. Flores I, Casaseca T, Martinez AC, Kanoh H, Merida I. Phosphatidic acid generation through interleukin 2 (IL-2)-induced alpha-diacylglycerol kinase activation is an essential step in IL-2-mediated lymphocyte proliferation. $J$ Biol Chem. (1996) 271:10334-40. doi: 10.1074/jbc.271.17.10334

103. Wada I, Kai M, Imai S, Sakane F, Kanoh H. Translocation of diacylglycerol kinase alpha to the nuclear matrix of rat thymocytes and peripheral T-lymphocytes. FEBS Lett. (1996) 393:48-52. doi: 10.1016/0014-5793(96)00857-5

104. Baldanzi G, Pighini A, Bettio V, Rainero E, Traini S, Chianale F, et al. SAP-mediated inhibition of diacylglycerol kinase alpha regulates TCR-induced diacylglycerol signaling. J Immunol. (2011) 187:594151. doi: 10.4049/jimmunol.1002476

105. Matsubara T, Ikeda M, Kiso Y, Sakuma M, Yoshino K, Sakane F, et al. cAbl tyrosine kinase regulates serum-induced nuclear export of diacylglycerol kinase alpha by phosphorylation at Tyr-218. J Biol Chem. (2012) 287:550717. doi: 10.1074/jbc.M111.296897

106. Sanjuan MA, Jones DR, Izquierdo M, Merida I. Role of diacylglycerol kinase alpha in the attenuation of receptor signaling. J Cell Biol. (2001) 153:207-20. doi: 10.1083/jcb.153.1.207

107. Sanjuan MA, Pradet-Balade B, Jones DR, Martinez AC, Stone JC, GarciaSanz JA, et al. T cell activation in vivo targets diacylglycerol kinase alpha to the membrane: a novel mechanism for Ras attenuation. J Immunol. (2003) 170:2877-83. doi: 10.4049/jimmunol.170.6.2877

108. Arranz-Nicolas J, Ogando J, Soutar D, Arcos-Perez R, Meraviglia-Crivelli D, Manes S, et al. Diacylglycerol kinase alpha inactivation is an integral component of the costimulatory pathway that amplifies TCR signals. Cancer Immunol Immunother. (2018) 67:965-80. doi: 10.1007/s00262-0182154-8

109. Merino E, Sanjuan MA, Moraga I, Cipres A, Merida I. Role of the diacylglycerol kinase alpha-conserved domains in 
membrane targeting in intact $\mathrm{T}$ cells. J Biol Chem. (2007) 282:35396-404. doi: 10.1074/jbc.M702085200

110. Merino E, Avila-Flores A, Shirai Y, Moraga I, Saito N, Merida I. Lck-dependent tyrosine phosphorylation of diacylglycerol kinase alpha regulates its membrane association in T cells. J Immunol. (2008) 180:580515. doi: 10.4049/jimmunol.180.9.5805

111. Chauveau A, Le Floc'h A, Bantilan NS, Koretzky GA, Huse M. Diacylglycerol kinase alpha establishes $\mathrm{T}$ cell polarity by shaping diacylglycerol accumulation at the immunological synapse. Sci Signal. (2014) 7:ra82. doi: 10.1126/scisignal.2005287

112. Raben DM, Tu-Sekine B. Nuclear diacylglycerol kinases: regulation and roles. Front Biosci. (2008) 13:590-7. doi: 10.2741/2704

113. Ratti S, Ramazzotti G, Faenza I, Fiume R, Mongiorgi S, Billi AM, et al. Nuclear inositide signaling and cell cycle. Adv Biol Regul. (2018) 67:16. doi: 10.1016/j.jbior.2017.10.008

114. Liu K, Kunii N, Sakuma M, Yamaki A, Mizuno S, Sato M, et al. A novel diacylglycerol kinase alpha-selective inhibitor, CU-3, induces cancer cell apoptosis and enhances immune response. J Lipid Res. (2016) 57:36879. doi: 10.1194/jlr.M062794

115. Jiang Y, Sakane F, Kanoh H, Walsh JP. Selectivity of the diacylglycerol kinase inhibitor 3-[2-(4-[bis-(4-fluorophenyl)methylene]-1piperidinyl)ethyl]-2, 3-dihydro-2-thioxo-4(1H)quinazolinone (R59949) among diacylglycerol kinase subtypes. Biochem Pharmacol. (2000) 59:763-72. doi: 10.1016/s0006-2952(99)00395-0

116. Boroda S, Niccum M, Raje V, Purow BW, Harris TE. Dual activities of ritanserin and $\mathrm{R} 59022$ as $\mathrm{DG} \alpha$ inhibitors and serotonin receptor antagonists. Biochem Pharmacol. (2017) 123:29-39. doi: 10.1016/j.bcp.2016. 10.011

117. Franks CE, Campbell ST, Purow BW, Harris TE, Hsu KL. The ligand binding landscape of diacylglycerol kinases. Cell Chem Biol. (2017) 24:87080.e5. doi: 10.1016/j.chembiol.2017.06.007

118. Velnati S, Ruffo E, Massarotti A, Talmon M, Varma KSS, Gesu A, et al. Identification of a novel DGKalpha inhibitor for XLP1 therapy by virtual screening. Eur J Med Chem. (2019) 164:37890. doi: 10.1016/j.ejmech.2018.12.061

119. Hayashi D, Tsumagari R, Liu K, Ueda S, Yamanoue M, Sakane F, et al. Screening of subtype-specific activators and inhibitors for diacylglycerol kinase. J Biochem. (2019) 165:517-22. doi: 10.1093/jb/mvz008
120. Olmez I, Love S, Xiao A, Manigat L, Randolph P, McKenna BD, et al. Targeting the mesenchymal subtype in glioblastoma and other cancers via inhibition of diacylglycerol kinase alpha. Neuro Oncol. (2018) 20:192202. doi: 10.1093/neuonc/nox119

121. Velnati S, Massarotti A, Antona A, Talmon M, Fresu LG, Galetto AS, et al. Structure activity relationship studies on Amb639752: toward the identification of a common pharmacophoric structure for DG $\alpha$ inhibitors. J Enzyme Inhib Med Chem. (2020) 35:96-108. doi: 10.1080/14756366.2019.1684911

122. Ostuni R, Piccolo V, Barozzi I, Polletti S, Termanini A, Bonifacio S, et al. Latent enhancers activated by stimulation in differentiated cells. Cell. (2013) 152:157-71. doi: 10.1016/j.cell.2012.12.018

123. Zeybel M, Hardy T, Wong YK, Mathers JC, Fox CR, Gackowska A, et al. Multigenerational epigenetic adaptation of the hepatic wound-healing response. Nat Med. (2012) 18:1369-77. doi: 10.1038/nm.2893

124. Zeybel M, Luli S, Sabater L, Hardy T, Oakley F, Leslie J, et al. A proofof-concept for epigenetic therapy of tissue fibrosis: inhibition of liver fibrosis progression by 3-deazaneplanocin A. Mol Ther. (2017) 25:21831. doi: 10.1016/j.ymthe.2016.10.004

125. Valinciute G, Weigel C, Veldwijk MR, Oakes CC, Herskind C, Wenz F, et al. BET-bromodomain inhibitors modulate epigenetic patterns at the diacylglycerol kinase alpha enhancer associated with radiation-induced fibrosis. Radiother Oncol. (2017) 125:168-74. doi: 10.1016/j.radonc.2017.08.028

126. Duong TE, Hagood JS. Epigenetic regulation of myofibroblast phenotypes in fibrosis. Curr Pathobiol Rep. (2018) 6:79-96. doi: 10.1007/s40139-018-0155-0

Conflict of Interest: The authors declare that the research was conducted in the absence of any commercial or financial relationships that could be construed as a potential conflict of interest.

Copyright (c) 2020 Liu, Schmezer and Popanda. This is an open-access article distributed under the terms of the Creative Commons Attribution License (CC BY). The use, distribution or reproduction in other forums is permitted, provided the original author(s) and the copyright owner(s) are credited and that the original publication in this journal is cited, in accordance with accepted academic practice. No use, distribution or reproduction is permitted which does not comply with these terms. 